\author{
Soroor SADRI, PhD \\ E-mail: sorsad58@yahoo.com \\ Department of Mathematics, Islamic Azad University \\ Karaj Branch, Karaj, Iran \\ Professor Mohsen ROSTAMY - MALKHALIFEH, PhD \\ E-mail: mohsen_rostamy@yahoo.com(Corresponding author) \\ Department of Mathematics, Science and Research Branch \\ Islamic Azad University, Tehran, Iran
}

\title{
CALCULATION OF COST EFFICIENCY BY INVERSE LINEAR PROGRAMMING WITH TWO-STAGE STRUCTURE
}

\begin{abstract}
Data envelopment analysis (DEA) is a linear programming technique which measures the relative efficiency of the decision making units (DMUs) based on input and output data. One of the applications of data envelopment analysis is calculation of cost efficiency. The methods used for calculation of cost efficiency in DEA are often minimizing production costs. These methods lack sufficient efficiency in system evaluation (including network systems) as they ignore the internal structure of the units and their intermediate products. In this regard, the present study introduced an inverse linear programming and used that in cost efficiency calculations to propose a new method which considers the network structure of the units. In this way, the proposed method can determine the optimal prices and proper costs to make the desired unit more efficient.
\end{abstract}

Keywords: Data envelopment analysis, Cost efficiency, Inverse linear programming, Two stage structure.

\section{JEL Classification C61,C60}

\section{Introduction}

Efficiency assessment has been always considered in evaluation of the production companies. Farrell (1975) using a method like efficiency measurement in engineering fields, calculated the efficiency of a production unit. Charnes et al (1978) developed the Farell's idea and proposed a pattern called data envelop analysis. This pattern was able to measure the efficiency with several inputs and outputs. In fact, DEA is a non-parametric method to measure the relative efficiency of the decision making units with multiple inputs and outputs through use of mathematical and linear programming. The real structure of decision making units 
is very complicated and is not just like a box with inputs and outputs. These units include interacting subunits with intermediate values (intermediate products) which are the input of one stage and the output of the other. Conventional DEA methods are inefficient in evaluation of the performance of such units due to ignoring the internal processes. Therefore they fail to provide the required knowledge to the managers. To overcome this problem, network data envelop analysis was introduced which can provide the possibility of assessing the efficiency of each unit and investigating their internal processes. Fare and Grosskopf (2000) introduced the network insight for the first time which was developed by the other researchers. In contrary with the traditional models, network DEA models do not have standard form and their model depends on the structure of the decision making unit, the interaction of the subunits and type of inputs and outputs (see Kao 2014). The communication structure of the subunits could be simple or complicated but the two-stage structure used in this study has a simple and basic network structure and many of the properties of network efficiency can be obtained by generalization of this relation. Seiford and Zhu (1999) used a two-stage process to evaluate the performance of 55 banks in US. To calculate the efficiency of the stages and total efficiency, traditional models were used separately and independently. Kao and Hwang (2008) presented a different method to evaluate the performance of two-stage systems with secrete relationships. Their method showed the effect of intermediate products on the total efficiency. In their proposed method was defined as the multiplication of the stages' efficiency. Chen et al. (2009) proposed a model similar to that of Kao and Hwang (2008) the only difference was that the total efficiency of the two-stage system was the summation of the stages efficiency; and they could use it in two states of fixed and varying scale efficiency. Despotis and Koronakos (2014) introduced a new method for determining the efficiency of two-stage systems which did not have the drawbacks of multiplying and summing methods. In this study, we proposed a two-stage structure for calculation of cost efficiency using inverse linear programming for a two-stage system.

Inverse linear programming has been used in cases with optimization model in which determination of weights or capacities was difficult, if the optimal solution is determined by some experiments or experiences, then we can determine the variables. Inverse linear programming was investigated by Zhang and Liu (1996). Yang and Zhang (1999) proposed two general methods for inverse optimization of summation models. In a study, Sadri, Rostamy and Shoja (2017) 
Calculation of Cost Efficiency by Inverse Linear Programming with Two-stage Structure

used inverse linear programming for data envelop analysis and obtained the proper costs for efficient units but lacked cost efficiency.

In this study, it was tried to develop the proper cost in a network structure for a two-stage process using inverse optimization problem. In reality, most of DMUs possess two- or multistage processes. Classic DEA methods do not consider intermediate stages in calculation of efficiency; this means that inputs are used for production of outputs regardless of internal interactions. In fact, classic DEA methods calculate efficiency just like a black box. In this study, by consideration of intermediate stages, we calculated the proper cost to make the inefficient units more efficient.

The rest of paper is organized as follows, in the second section, inverse linear programming is expressed. Cost model with two-stage structure is explained in the third section, then the inverse cost model is presented with two-stage structure and the proposed model was tested using a numerical example. The next section presents a model in which the prices were considered as the intermediate inputs. It was then numerically assessed. The conclusions are made in the last section.

\section{Inverse linear programming}

Inverse optimization problem was first addressed by researchers in geophysics. However, mathematical scientists showed more enthusiasts for that. In recent years, inverse optimization problem has drawn a considerable attention among engineers and mathematicians due to its numerous applications.

Now using inverse linear programming presented by Zhang and Liu (1996), we show the series of possible solutions by S. suppose that $x^{0}$ is a possible answer and $c, x \in \mathbb{R}^{n}, b \in \mathbb{R}^{m}$ and $A$ is a mxn matrix. Consider following problem:

$\min \mathrm{cx}$

s. t: $\quad A x=b$

$$
x \geq 0
$$

We want to modulate $\mathrm{c}$ in a way that $\mathrm{x}^{\mathrm{o}}$ becomes the optimal answer for problem (1). We define:

$\mathcal{F}\left(\mathrm{x}^{\mathrm{o}}\right)=\left\{\tilde{\mathrm{c}} \in \mathbb{R}^{\mathrm{n}} \mid \min \{\tilde{\mathrm{c} x} \mid \mathrm{Ax}=\mathrm{b}, \mathrm{x} \geq 0\}=\tilde{\mathrm{c}} \mathrm{x}^{0}\right\}$

So, the inverse optimization problem corresponding to problem (1) will be defined as: $\min \left\{\|\tilde{\mathrm{c}}-\mathrm{c}\|_{p} \mid \tilde{\mathrm{c}} \in \mathcal{F}\left(\mathrm{x}^{0}\right)\right\}$.

In which $\|.\|_{p}$ is the proper norm of the problem. 
Inverse linear programming disturbs the target function to $\tilde{c}$. in a way that possible point of $x^{0}$ will be the optimal answer of the problem in respect of vector $\tilde{\mathrm{c}}$ with minimum distance to $\mathrm{c}$ vector. Therefore the aim is minimization of $\|\tilde{c}-\mathrm{c}\|$.

\section{Two-stage structure}

Two-stage production systems are the simplest form of production systems with network structure in which the stages are interacting with each other in serial manner. Numerous studies have addressed two-stage systems in DEA reflecting its importance in efficiency evaluation of DMUs in various industries.

In the first stage of two-stage systems, inputs are used for production of outputs called intermediate products which will be used as the input of the second stage to reach to the final output.

Suppose $\mathrm{n}$ DMUs with two-stage structure. The first stage uses $\mathrm{m}$ inputs for production on $\mathrm{q}$ intermediate products. The second stage uses the output of the first stage as its input and produce $\mathrm{s}$ final outputs. Assume that for each $\mathrm{DMU}_{j}$ $(j=1, \ldots, n)$, the input vector of the first stage has the form of $x_{i j}(i=1, \ldots, m)$. The values of intermediate vector are in form of $Z_{\mathrm{dj}}(\mathrm{d}=1, \ldots, \mathrm{D})$ and the output of the second step is in form of $y_{r j}(r=1, \ldots, s)$.

CCR model assesses the system efficiency while ignoring the two-stage structure and the relationships between the stages. The work of Kao and Hwang (2008) can be regarded as one of the important researches in the field of efficiency evaluation of two-stage production systems. By adding the corresponding operation of each stage to fractional CCR model, they managed to modify the performance of the two-stage systems and presented following model:

$$
\begin{aligned}
& E_{k}= \underset{u, v, w}{\operatorname{Max}} \frac{u^{t} y_{k}}{v^{t} x_{k}} \\
& \text { s.t } \quad \frac{u^{t} y_{j}}{v^{t} x_{j}} \leq 1 \quad j=1, \ldots, n \\
& \frac{u^{t} y_{j}}{w^{t} z_{j}} \leq 1 \quad j=1, \ldots, n \\
& \frac{w^{t} z_{j}}{v^{t} x_{j}} \leq 1 \quad j=1, \ldots, n \\
& u, v, w \geq 0
\end{aligned}
$$


Calculation of Cost Efficiency by Inverse Linear Programming with Two-stage Structure

Regarding model (2), the first constraint can be obtained from the second and third constraint. Therefore the first constraint can be eliminated from the model. It must be noted that the main assumption in model (2) is that the assigned weight of the intermediate products is the same in both stages; although they act as the output and input in the first and second stages, respectively. The dual nature of the intermediate products results in a condition in which the total efficiency of the system is equal with the multiplication of stages' efficiency $\left(E_{k}=E_{k}^{1} \times E_{k}^{2}\right)$. In fact the model of Kao and Hwang (2008) describes the physical relationship between the main process and its sub-processes. Using Charnes and Cooper (1962) transformations, the linear form of model (2) can be expressed ad model (3).

$$
\begin{aligned}
\mathrm{E}_{\mathrm{K}}=\max & \sum_{\mathrm{r}=1}^{\mathrm{s}} \mathrm{u}_{\mathrm{r}} \mathrm{Y}_{\mathrm{rk}} \\
\text { s.t. } & \sum_{\mathrm{i}=1}^{\mathrm{m}} \mathrm{v}_{\mathrm{i}} \mathrm{x}_{\mathrm{ik}}=1 \\
& \sum_{\mathrm{d}=1}^{\mathrm{D}} \mathrm{w}_{\mathrm{d}} \mathrm{z}_{\mathrm{dj}}-\sum_{\mathrm{i}=1}^{\mathrm{m}} \mathrm{v}_{\mathrm{i}} \mathrm{x}_{\mathrm{ij}} \leq 0 \quad \mathrm{j}= \\
1, \ldots, \mathrm{n}, \quad & (3) \\
& \sum_{\mathrm{r}=1}^{\mathrm{s}} \mathrm{u}_{\mathrm{r}} \mathrm{y}_{\mathrm{rj}}-\sum_{\mathrm{d}=1}^{\mathrm{D}} \mathrm{w}_{\mathrm{d}} \mathrm{z}_{\mathrm{dj}} \leq 0 \quad \mathrm{j}=1, \ldots, \mathrm{n}, \\
& \mathrm{u}_{\mathrm{r}}, \mathrm{v}_{\mathrm{i}}, \mathrm{w}_{\mathrm{d}} \geq 0, \mathrm{r}=1, \ldots, \mathrm{s} ; \mathrm{i}=1, \ldots, \mathrm{m} ; \mathrm{d}=1, \ldots, \mathrm{D} .
\end{aligned}
$$

Kao and Hwang model is a radial model. This means that the variation in inputs and outputs are with the similar ratio which can be used in evaluation of the two-stage production systems. This model can be only applied for efficiency in fixed scale.

\section{The problem of inverse linear programming of cost model with a two-stage structure}

In this section, the cost efficiency model will be presented by inverse linear programming.

For Kao and Hwang (2008) model, the efficiency of a two-stage system can be expressed as follows. Considering dual model of (3), its coverage form will be:

$\min \theta$

$$
\begin{aligned}
& \text { s.t. } \sum_{j=1}^{n} \lambda_{j} x_{i j} \leq \theta x_{i o} \quad i=1, \ldots, m \\
& \sum_{j=1}^{n}\left(\lambda_{j}-\mu_{j}\right) z_{p j} \geq 0 \quad p=1, \ldots, q \\
& \sum_{\mathrm{j}=1}^{\mathrm{n}} \mu_{\mathrm{j}} \mathrm{y}_{\mathrm{rj}} \geq \mathrm{y}_{\mathrm{ro}} \quad \mathrm{r}=1, \ldots, \mathrm{s} \\
& \mu_{\mathrm{j}^{\prime}}, \lambda \geq 0 \quad \mathrm{j}=1, \ldots, \mathrm{n}
\end{aligned}
$$


Now, using efficiency of two-stage system, cost model can be defined for a twostage system:

$\min \mathrm{CX}$

$$
\begin{array}{cc}
\text { s.t. } \sum_{j=1}^{n} \lambda_{j} x_{i j} \leq x_{i} & i=1, \ldots, m \\
\sum_{j=1}^{n}\left(\lambda_{j}-\mu_{j}\right) z_{p j} \geq 0 & p=1, \ldots, q \\
\sum_{j=1}^{n} \mu_{j} y_{r j} \geq y_{r o} & r=1, \ldots, s \\
\mu_{j}, \lambda_{j} \geq 0 & j=1, \ldots, n
\end{array}
$$

Definition 1: assume $\left(x^{*}, \lambda^{*}, \mu^{*}\right)$ is the optimal solution of the model. The efficiency of the evaluated unit can be defined as:

$$
\begin{aligned}
\mathrm{E}_{\mathrm{C}}= & \frac{\sum_{\mathrm{i}=1}^{\mathrm{m}} \mathrm{C}_{\mathrm{io}} \mathrm{x}_{\mathrm{i}}^{*}}{\sum_{\mathrm{i}=1}^{\mathrm{m}} \mathrm{C}_{\mathrm{io}} \mathrm{x}_{\mathrm{io}}} \\
& , 0<\mathrm{E}_{\mathrm{Cj}} \leq 1
\end{aligned}
$$

The evaluated unit is cost-efficient iff $\mathrm{E}_{\mathrm{C}}=1$.

Suppose that $\left(\mathrm{x}^{0}, \lambda^{0}, \mu^{0}\right)$ is the possible solution for model (5), $\mathrm{U}_{\mathrm{r}}$ is the dual variable of rth constraint (c) and $V_{i}$ is the dual variable of ith constraint (a) and $\mathrm{W}_{\mathrm{p}}$ is the dual variable of pth constraint (b). Dual model (5) has the following form:

$$
\begin{aligned}
& \max \sum_{\mathrm{r}=1}^{\mathrm{s}} \mathrm{U}_{\mathrm{r}} \mathrm{y}_{\mathrm{ro}} \\
& \text { s.t. } \sum_{p=1}^{q} W_{p} z_{p j}-\sum_{i=1}^{m} V_{i} x_{i j} \leq 0 \quad j=1, \ldots, n \\
& \sum_{\mathrm{r}=1}^{\mathrm{s}} \mathrm{U}_{\mathrm{r}} \mathrm{y}_{\mathrm{rj}}-\sum_{\mathrm{p}=1}^{\mathrm{q}} \mathrm{W}_{\mathrm{p}} \mathrm{z}_{\mathrm{pj}} \leq 0 \quad \mathrm{j}=1, \ldots, \mathrm{n} \\
& \mathrm{U}_{\mathrm{r}} \geq 0 \quad \mathrm{r}=1, \ldots, \mathrm{s}, \mathrm{V}_{\mathrm{i}} \geq 0 \quad \mathrm{i}=1, \ldots, \mathrm{m}, \mathrm{W}_{\mathrm{p}} \geq 0 \quad \mathrm{p}=1, \ldots, \mathrm{q}
\end{aligned}
$$

Using Karush-Kuhn-Tucker (K.K.T) optimality conditions, following conditions should be met.

1 - Is the initial possible solution

$2-(\mathrm{U}, \mathrm{V})$ is the dual possible solution 
Calculation of Cost Efficiency by Inverse Linear Programming with Two-stage Structure

3- The condition of complementary slackness holds.

Strong complementary slackness condition (SCSC):

1) if $\sum_{j=1}^{n} \lambda_{j} x_{i j}<x_{i}$ then $\quad V_{i}=0$

2)if $\sum_{j=1}^{n} \lambda_{j} y_{r j}>y_{r o}$ then $\quad U_{r}=0$

We perturbed target function of $\mathrm{C}$ to vector $\mathrm{V}$ in a way that the possible point becomes optimum relative to $\mathrm{V}$. therefore, the goal is to minimize $\|\mathrm{C}-\mathrm{V}\|$, we used norm 1 to optimize $\|\mathrm{C}-\mathrm{V}\|$. The problem of inverse linear programming of two-stage cost will be expressed by following equation using K.K.T optimal condition:

$$
\begin{array}{cc}
\min \|C-V\|=\min \sum_{i=1}^{m}\left|C_{i}-V_{i}\right| & i=1, \ldots, m \\
\text { s.t. } \sum_{j=1}^{n} \lambda_{j} x_{i j} \leq x_{i o} & p=1, \ldots, q \\
\sum_{j=1}^{n}\left(\lambda_{j}-\mu_{j}\right) z_{p j} \geq 0 & r=1, \ldots, s \\
\sum_{j=1}^{n} \mu_{j} y_{r j} \geq y_{r o} & j=1, \ldots, n \\
\sum_{p=1}^{q} W_{p} z_{p j}-\sum_{i=1}^{m} V_{i} x_{i j} \leq 0 & j=1, \ldots, n \\
\sum_{r=1}^{s} U_{r} y_{r j}-\sum_{p=1}^{q} W_{p} z_{p j} \leq 0 & i=1, \ldots, m \\
V_{i}\left(x_{i o}-\sum_{j=1}^{n} \lambda_{j} x_{i j}\right)=0 & p=1, \ldots, q \\
W_{p}\left(\sum_{j=1}^{n}\left(\lambda_{j}-\mu_{j}\right) z_{p j}\right)=0 & r=1, \ldots, s \\
U_{r}\left(\sum_{j=1}^{n} \mu_{j} y_{r j}-y_{r o}\right)=0 &
\end{array}
$$




$$
\begin{array}{ll}
\lambda_{j}\left(\sum_{p=1}^{q} W_{p} z_{p j}-\sum_{i=1}^{m} V_{i} x_{i j}\right)=0 & j=1, \ldots, n \\
\mu_{j}\left(\sum_{r=1}^{s} U_{r} y_{r j}-\sum_{p=1}^{q} W_{p} z_{p j}\right)=0 & j=1, \ldots, n \\
\lambda_{j} \geq 0 \quad j=1, \ldots, n \\
U_{r} \geq 0 \quad r=1, \ldots, s, \quad W_{p} \geq 0 & p=1, \ldots, q \\
V_{i} \geq 0 & i=1, \ldots, m
\end{array}
$$

Model (9) is nonlinear which will be transformed to linear problem using a variable change.

$$
\begin{aligned}
& t_{\mathrm{i}}=\mathrm{C}_{\mathrm{i}}-\mathrm{V}_{\mathrm{i}}, t_{\mathrm{i}}=\alpha_{\mathrm{i}}-\beta_{\mathrm{i}} \\
& \alpha_{\mathrm{i}}, \beta_{\mathrm{i}} \geq 0 \\
& \rho_{i j}=\mathrm{V}_{\mathrm{i}} \lambda_{\mathrm{j}}, \quad \mathrm{i}=1, \ldots, \mathrm{m} \\
& \mathrm{K}_{\mathrm{rj}}=\mathrm{U}_{\mathrm{r}} \boldsymbol{\mu}_{\mathrm{j}} \quad, \mathrm{W}_{\mathrm{p}} \boldsymbol{\mu}_{\mathrm{pj}}=\mathrm{W}_{\mathrm{p}} \lambda_{\mathrm{j}} \\
& \mathrm{i}=1, \ldots, \mathrm{m}, \quad \mathrm{j}=1, \ldots, \mathrm{n}, \quad \mathrm{p}=1, \ldots, \mathrm{q}
\end{aligned}
$$

Changing the variables of (10), the problem of linear programming will be:

$$
\begin{array}{cc}
\min \sum_{i=1}^{m}\left(\alpha_{i}+\beta_{i}\right) & \\
\text { s.t. } \quad \sum_{j=1}^{n} \rho_{i j} x_{i j} \leq V_{i} x_{i o} & i=1, \ldots, m \\
\sum_{j=1}^{n}\left(Y_{p j}-K_{p j}\right) z_{p j} \geq 0 & p=1, \ldots, q \\
\sum_{j=1}^{n} \eta_{r j} y_{r j} \geq U_{r} y_{r o} & r=1, \ldots, s \\
\sum_{p=1}^{q} Y_{p j} z_{p j}-\sum_{i=1}^{m} \rho_{i j} x_{i j} \leq 0 & j=1, \ldots, n \\
\sum_{r=1}^{s} \eta_{r j} y_{r j}-\sum_{p=1}^{q} K_{p j} z_{p j} \leq 0 & i=1, \ldots, n \\
V_{i} x_{i o}-\sum_{j=1}^{n} \rho_{i j} x_{i j}=0 & p=1, \ldots, m \\
\sum_{j=1}^{n}\left(Y_{p j}-K_{p j}\right) z_{p j}=0 & r=1, \ldots, s \\
\sum_{j=1}^{n} \eta_{r j} y_{r j}-U_{r} y_{r o}=0 &
\end{array}
$$


Calculation of Cost Efficiency by Inverse Linear Programming with Two-stage Structure

$$
\begin{array}{cc}
\sum_{p=1}^{\mathrm{q}} \mathrm{Y}_{\mathrm{pj}} \mathrm{z}_{\mathrm{pj}}-\sum_{\mathrm{i}=1}^{\mathrm{m}} \rho_{\mathrm{ij}} \mathrm{x}_{\mathrm{ij}}=0 & \mathrm{j}=1, \ldots, \mathrm{n} \\
\sum_{\mathrm{r}=1}^{\mathrm{s}} \eta_{\mathrm{rj}} \mathrm{y}_{\mathrm{rj}}-\sum_{\mathrm{p}=1}^{\mathrm{q}} \mathrm{K}_{\mathrm{pj}} \mathrm{z}_{\mathrm{pj}}=0 & \mathrm{j}=1, \ldots, \mathrm{n} \\
\mathrm{V}_{\mathrm{i}}=\mathrm{C}_{\mathrm{i}}-\alpha_{\mathrm{i}}+\beta_{\mathrm{i}} & \mathrm{i}=1, \ldots, \mathrm{m} \\
\mathrm{P}_{\mathrm{ij}} \geq 0 \quad \mathrm{j}=1, \ldots, \mathrm{n}, \mathrm{i}=1, \ldots, \mathrm{m} & \\
\mathrm{V}_{\mathrm{i}}, \alpha_{\mathrm{i}}, \beta_{\mathrm{i}} \geq 0 & \mathrm{i}=1, \ldots, \mathrm{m} \\
\mathrm{U}_{\mathrm{r}} \geq 0 \quad, \eta_{\mathrm{rj}} \geq 0 \quad, \mathrm{r}=1, \ldots, \mathrm{s}, \mathrm{j}=1, \ldots, \mathrm{n} & \\
\mathrm{K}_{\mathrm{pj}}, \mathrm{Y}_{\mathrm{pj}} \geq 0 \quad \mathrm{p}=1, \ldots, \mathrm{q} \quad, \mathrm{j}=1, \ldots, \mathrm{n} &
\end{array}
$$

5. Numerical example 1: Table 1 presents the data of 20 units including 2 inputs, 2 intermediate values and 2 outputs. The costs of first and second inputs are 170.45 and 345.4, respectively. The results are listed in Table 2.

Table 1. Data for 20 DMU

\begin{tabular}{ccccccc}
\hline $\begin{array}{c}\text { DM } \\
\mathbf{U}\end{array}$ & $\begin{array}{r}\text { Input } \\
\mathbf{1}\end{array}$ & $\begin{array}{r}\text { Input } \\
\mathbf{2}\end{array}$ & $\begin{array}{r}\text { Intermediat } \\
\mathbf{e 1}\end{array}$ & $\begin{array}{r}\text { Intermediat } \\
\mathbf{e 2}\end{array}$ & $\begin{array}{r}\text { Output } \\
\mathbf{1}\end{array}$ & $\begin{array}{r}\text { Output } \\
\mathbf{2}\end{array}$ \\
\hline 1 & 100 & 101 & 673 & 193.8 & 1332 & 1044 \\
2 & 140 & 112 & 686 & 432 & 1799 & 989 \\
3 & 114 & 198 & 422 & 270 & 720 & 720 \\
\hline 4 & 92 & 86 & 569 & 220.1 & 997 & 1052 \\
5 & 214 & 411 & 606 & 152 & 637 & 656 \\
\hline 6 & 134 & 230 & 288 & 133.4 & 520 & 570 \\
7 & 211 & 236 & 405 & 372.7 & 413 & 580 \\
\hline 8 & 146 & 237 & 432 & 115.2 & 388 & 642 \\
9 & 60 & 95 & 390 & 185 & 288 & 835 \\
10 & 551 & 111 & 345 & 56.9 & 455 & 301 \\
11 & 69 & 81 & 220 & 46.4 & 146 & 160 \\
\hline 12 & 86 & 200 & 268 & 64.5 & 251 & 347 \\
13 & 31 & 110 & 179 & 170 & 323 & 434 \\
14 & 83 & 93 & 336 & 215 & 188 & 187 \\
15 & 69 & 133 & 202 & 69.4 & 238 & 208 \\
\hline 16 & 75 & 98 & 388 & 137.1 & 336 & 206 \\
\hline
\end{tabular}


Soroor Sadri, Mohsen Rostamy- Malkhalifeh

\begin{tabular}{lllllll}
\hline 17 & 79 & 101 & 228 & 41 & 195 & 306 \\
18 & 83 & 79 & 287 & 84 & 182 & 189 \\
19 & 53 & 79 & 215 & 70 & 121 & 413 \\
20 & 75 & 65 & 304 & 300 & 804 & 265 \\
\hline
\end{tabular}

The efficiency of the data in Table (2) was calculated by model (4) as presented in the second column of Table (2). Minimum cost was also calculated using model (5) and listed in the third column while the cost of each unit is provided in the fourth column. Cost efficiency of the units is presented in the fifth column as was calculated using equation (6). Target function of the inverse model (9) was calculated for the two-stage structure as reported in the sixth column. As Table( 2) suggests, units 9, 4, 2, 1 and 13 are CCR efficient and only unit 2 is cost-efficient. Now, using inverse linear programming model, 20 units were investigated. It was observed that the value of target function for CCR-inefficient units $(14,12,11,10$, $8,7,6,5,3,19,18,17,16,15$ and 20) as well as the cost were obtained zero. This means that it is impossible to obtain the cost of these units while they are efficient. The units which are both CCR- and cost-efficient (such as unit 2) showed to have zero target function and their cost was obtained the same as the previous cost.

Table 2. Computational results for $20 \mathrm{DMU}$

\begin{tabular}{cccccccc}
\hline DMU & Model(4) & Model(5) & $\begin{array}{c}\text { Cost of each } \\
\text { unit }\end{array}$ & $\begin{array}{c}\text { Efficiency } \\
\text { Cost(6) }\end{array}$ & Model(9) & $\mathbf{V}_{\mathbf{1}}$ & $\mathbf{V}_{\mathbf{2}}$ \\
\hline 1 & 1 & 51539.34 & 51980.4 & 0.9916 & 100.98 & 271.9299 & 345.3998 \\
\hline 2 & 1 & 62617.80 & 62617.8 & 1 & 0 & 170.95 & 345.4 \\
\hline 3 & 0.5100204 & 31451.11 & 87877.5 & 0.3579 & 516.350 & 0 & 0 \\
\hline 4 & 1 & 44998.72 & 45431.8 & 0.9905 & 216.5516 & 170.95 & 128.8484 \\
\hline 5 & 0.2442532 & 28325.60 & 178542.7 & 0.1587 & 516.350 & 0 & 0 \\
\hline 6 & 0.3296945 & 24030.75 & 102349.3 & 0.2348 & 516.350 & 0 & 0 \\
\hline 7 & 0.2251284 & 23850.27 & 117584.85 & 0.2028 & 516.350 & 0 & 0 \\
\hline 8 & 0.3266750 & 26041.26 & 106818.5 & 0.2438 & 516.350 & 0 & 0 \\
\hline 9 & 1 & 32746.60 & 43070 & 0.7603 & 303.8538 & 170.95 & 41.54628 \\
\hline 10 & 0.2749582 & 16529.19 & 132532.85 & 0.1247 & 516.350 & 0 & 0 \\
\hline 11 & 0.1925106 & 6746.084 & 39772.95 & 0.1696 & 516.350 & 0 & 0 \\
\hline
\end{tabular}


Calculation of Cost Efficiency by Inverse Linear Programming with Two-stage Structure

\begin{tabular}{cccccccc}
\hline 12 & 0.2979956 & 14289.32 & 83781.7 & 0.1706 & 516.350 & 0 & 0 \\
\hline 13 & 1 & 17918.97 & 43293.45 & 0.4139 & 339.8760 & 170.95 & 5.524068 \\
14 & 0.1938170 & 8185.913 & 46311.05 & 0.1768 & 516.350 & 0 & 0 \\
15 & 0.2595383 & 9684.728 & 57733.75 & 0.1677 & 516.350 & 0 & 0 \\
16 & 0.3106000 & 11984.72 & 46670.45 & 0.2568 & 516.350 & 0 & 0 \\
17 & 0.3044475 & 12464.37 & 48390.45 & 0.2576 & 516.350 & 0 & 0 \\
18 & 0.1994370 & 8134.391 & 41475.45 & 0.1961 & 516.350 & 0 & 0 \\
19 & 0.5685612 & 16196.82 & 36346.95 & 0.4456 & 516.350 & 0 & 0 \\
\hline 20 & 0.8122464 & 27984.83 & 35272.25 & 0.79339509 & 516.350 & 0 & 0 \\
\hline
\end{tabular}

For CCR-efficient units which are not cot-efficient (like units 9, 4, 1 and 13), the value of the target function was different. For unit 1 , the value of the inverse model target function was 100.98 and its first and second input cost values were 271.9299 and 345.3998 , respectively. This means that if we change the cost of first and second inputs to these values, the unit will be cost-efficient. The same trend holds for units 4, 9 and 13 which showed different values in Table 2. With the newly obtained costs, the technically efficient units which were not costefficient can become cost-efficient if they employ the new price vectors.

\section{Inverse model for two-stage structure by consideration of intermediate input cost}

In some cases of two-stage systems, intermediate input has some costs (such as warehouse costs) which may be effective in calculation of cost efficiency. In this section, we suppose that the first input has costs and the intermediate product of the first stage is the output with no cost. For the second stage however, it acts like an input and has costs. For this purpose, we developed the proposed inverse model of section 4 for cases where the intermediate input has costs. Consider $(\mathrm{i}=1, \ldots, \mathrm{m}) \mathrm{C}_{\mathrm{ij}}$ as the cost vector for the first stage input and $(p=1, \ldots, q) Q_{p j}$ as the cost vector for second stage input. Now, based on model (4) presented by Kao and Hwang (2008) for two-stage system efficiency, the cost of a two-stage system in which the intermediate input has cost can be expressed as: $\min \mathrm{CX}+\mathrm{QZ}$ 


$$
\begin{array}{lc}
\text { s.t: } \quad \sum_{j=1}^{n} \lambda_{j} x_{i j} \leq x_{i} & i=1, \ldots, m \\
\sum_{j=1}^{n}\left(\lambda_{j}-\mu_{j}\right) z_{p j} \geq 0 & p=1, \ldots, q
\end{array}
$$

Definition 2: assume $\left(\mathrm{x}^{*}, \mathrm{Z}^{*}, \lambda^{*}, \mu^{*}\right)$ is the optimal solution of the model. The efficiency of the evaluated unit can be defined as:

$\mathrm{E}_{\mathrm{C}}=\frac{\sum_{\mathrm{i}=1}^{\mathrm{m}} \mathrm{C}_{\mathrm{io}} \mathrm{x}_{\mathrm{i}}^{*}+\sum_{\mathrm{P}=1}^{\mathrm{q}} \mathrm{Q}_{\mathrm{po}} \mathrm{Z}_{\mathrm{p}}^{*}}{\sum_{\mathrm{i}=1}^{\mathrm{m}} \mathrm{C}_{\mathrm{io}} \mathrm{x}_{\mathrm{io}}+\sum_{\mathrm{P}=1}^{\mathrm{q}} \mathrm{Q}_{\mathrm{po}} \mathrm{Z}_{\mathrm{po}}}$

The evaluated unit is cost-efficient iff $\mathrm{E}_{\mathrm{C}}=1$.

Suppose that $\left(\mathrm{x}^{0}, \mathrm{Z}^{0}, \lambda^{0}, \mu^{0}\right)$ is the possible answer for model (12), $\mathrm{V}_{\mathrm{i}}$ is the dual variable for ith constraint (a), $W_{p}$ is the dual variable for pth constraint (b), $\mathrm{H}_{\mathrm{p}}$ denoted the dual variable for the pth constraint (c) and $U_{\mathrm{r}}$ represents the dual variable of rth constraint (d). Dual model of (12) has the following form:

$$
\begin{array}{ll}
\max \sum_{r=1}^{s} U_{r} y_{r o} & \\
\text { s.t. } \sum_{p=1}^{q} W_{p} z_{p j}-\sum_{i=1}^{m} V_{i} x_{i j} \leq 0 & j=1, \ldots, n \\
\sum_{r=1}^{s} U_{r} y_{r j}-\sum_{p=1}^{q}\left(H_{p}-W_{p}\right) z_{p j} \leq 0 & j=1, \ldots, n \\
V=C \quad, \quad H=Q \\
U_{r} \geq 0 \quad r=1, \ldots, s & \\
V_{i} \geq 0 & i=1, \ldots, m \\
H_{p}, W_{p} \geq 0 & p=1, \ldots, q
\end{array}
$$

The problem of inverse linear programming of cost with two-stage structure can be expressed in following form by use of K.K.T optimization condition:

$$
\begin{array}{lc}
\min (\|\mathrm{C}-\mathrm{V}\|+\|Q-H\|)=\min \left(\sum_{\mathrm{i}=1}^{\mathrm{m}}\left|\mathrm{C}_{\mathrm{i}}-\mathrm{V}_{\mathrm{i}}\right|+\sum_{\mathrm{p}=1}^{\mathrm{q}}\left|\mathrm{Q}_{\mathrm{p}}-\mathrm{H}_{\mathrm{p}}\right|\right) \\
\text { s.t. } \sum_{\mathrm{j}=1}^{\mathrm{n}} \lambda_{\mathrm{j}} \mathrm{x}_{\mathrm{ij}} \leq \mathrm{x}_{\mathrm{io}} & \mathrm{i}=1, \ldots, \mathrm{m}
\end{array}
$$


Calculation of Cost Efficiency by Inverse Linear Programming with Two-stage Structure

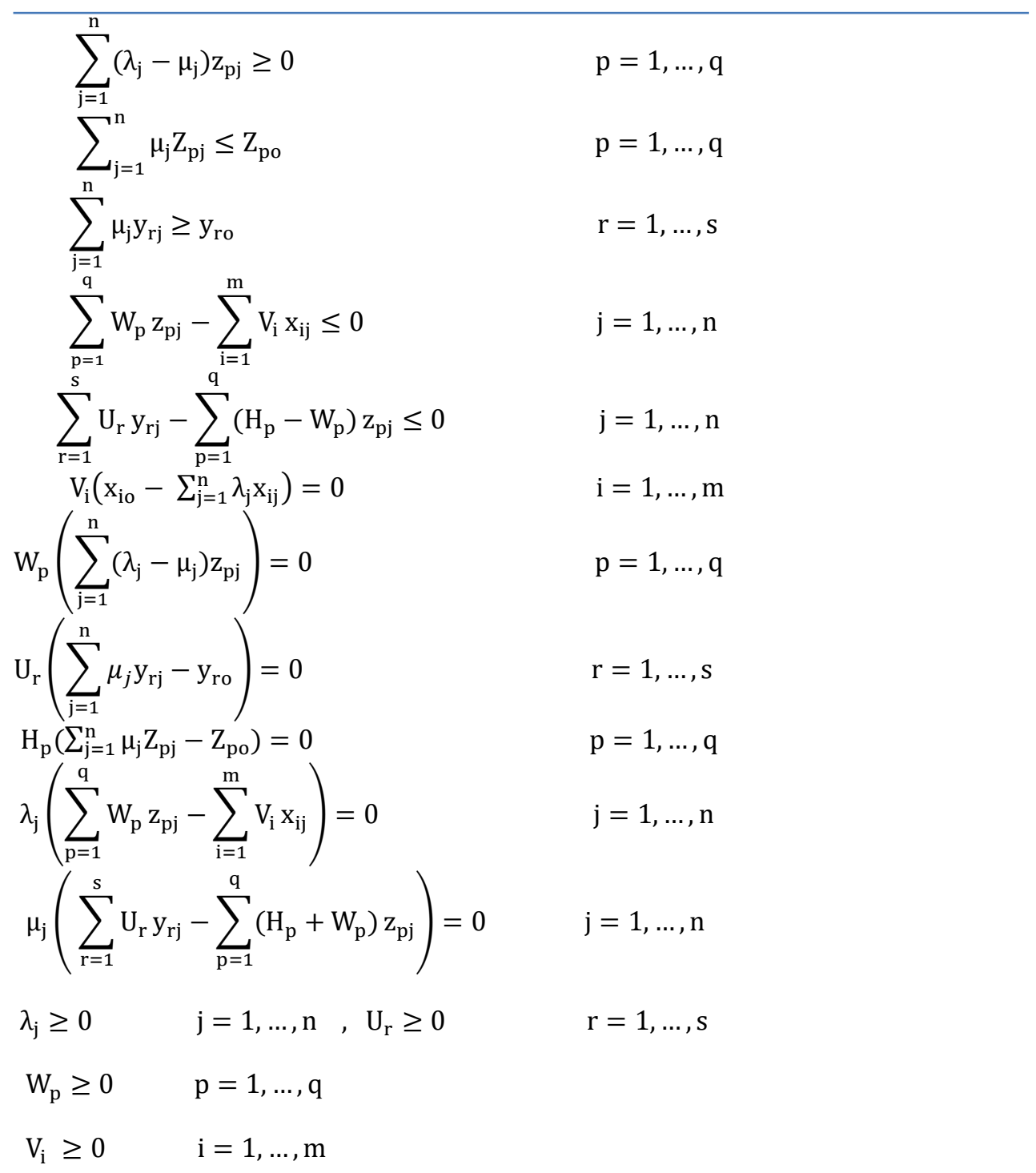

7. Numerical example 2: in this section, inverse model of (15) is investigated on the data of 20 DMUs. The data of Table (1) were used. In this example, the first and second input costs are similar for all the units and equal with 170.95 and 345.40, respectively. For the intermediate stage input, the costs of first and second stages are 120 and 180, respectively. The results are listed in Tables (3a and $3 b)$. 
Soroor Sadri, Mohsen Rostamy- Malkhalifeh

Table 3a. Computational results for 20 DMU

\begin{tabular}{|c|c|c|c|c|c|}
\hline DMU & Model(4) & Model(12) & $\begin{array}{c}\text { cost of } \\
\text { each unit }\end{array}$ & $\begin{array}{c}\text { Efficiency } \\
\text { Cost }(13)\end{array}$ & Model(15) \\
\hline 1 & 1 & 167624.4 & 167624.4 & 1 & 40.23862 \\
\hline 2 & 1 & 222697.8 & 222697.8 & 1 & $0.2040874 E-03$ \\
\hline 3 & 0.510020 & 106631.8 & 187117.5 & 0.5699 & 816.350 \\
\hline 4 & 1 & 153329.8 & 153329.8 & 1 & 0.0001 \\
\hline 5 & 0.244253 & 96299.77 & 278622.7 & 0.6716 & 816.350 \\
\hline 6 & 0.329694 & 82602.75 & 160921.3 & 0.5133 & 816.350 \\
\hline 7 & 0.225128 & 82052.01 & 233270.85 & 0.35175 & 816.350 \\
\hline 8 & 0.326675 & 89632.19 & 179394.5 & 0.4996 & 816.350 \\
\hline 9 & 1 & 112846.6 & 123170 & .91619 & 303.8538 \\
\hline 10 & 0.274958 & 56546.26 & 184174.85 & 0.3070 & 816.350 \\
\hline 11 & 0.192511 & 23187.56 & 74524.95 & 0.3111 & 816.350 \\
\hline 12 & 0.297996 & 49157.11 & 127551.7 & 0.3854 & 816.350 \\
\hline 13 & 1 & 61638.00 & 95373.45 & .6463 & 455.6604 \\
\hline 14 & 0.193817 & 27739.58 & 125331.01 & 0.22133 & 816.350 \\
\hline 15 & 0.259538 & 32158.35 & 94465.75 & 0.3404 & 816.350 \\
\hline 16 & 0.310600 & 41686.22 & 117908.45 & 0.3535 & 816.350 \\
\hline 17 & 0.304447 & 24139.01 & 83130.45 & 0.2904 & 816.350 \\
\hline 18 & 0.199437 & 27676.34 & 91035.45 & 0.3040 & 816.350 \\
\hline 19 & 0.568561 & 17095.41 & 74746.95 & 0.2288 & 816.350 \\
\hline 20 & 0.812246 & 36030.57 & 125752.25 & 0.2866 & 816.350 \\
\hline
\end{tabular}


Calculation of Cost Efficiency by Inverse Linear Programming with Two-stage Structure

\section{Table 3b. Computational results for 20 DMU}

\begin{tabular}{ccccc}
\hline DMU & $\mathbf{V}_{\mathbf{1}}$ & $\mathbf{V}_{\mathbf{2}}$ & $\mathbf{H}_{\mathbf{1}}$ & $\mathbf{H}_{\mathbf{2}}$ \\
\hline 1 & 170.9498 & 345.3969 & 119.9859 & 139.7787 \\
2 & 170.95 & 345.40 & 120 & 180
\end{tabular}

$\begin{array}{ccccc}3 & 0 & 0 & 0 & 0 \\ 4 & 170.95 & 345.40 & 120 & 180\end{array}$

$\begin{array}{ccccc}5 & 0 & 0 & 0 & 0 \\ 6 & 0 & 0 & 0 & 0\end{array}$

$\begin{array}{ccccc}7 & 0 & 0 & 0 & 0 \\ 8 & 0 & 0 & 0 & 0\end{array}$

$\begin{array}{ccccc}9 & 170.95 & 41.54628 & 120 & 180 \\ 10 & 0 & 0 & 0 & 0\end{array}$

$\begin{array}{ccccc}11 & 0 & 0 & 0 & 0 \\ 12 & 0 & 0 & 0 & 0\end{array}$

$\begin{array}{ccccc}13 & 170.95 & 28.65214 & 120 & 41.0875 \\ 14 & 0 & 0 & 0 & 0\end{array}$

$\begin{array}{ccccc}15 & 0 & 0 & 0 & 0 \\ 16 & 0 & 0 & 0 & 0\end{array}$

$\begin{array}{ccccc}17 & 0 & 0 & 0 & 0 \\ 18 & 0 & 0 & 0 & 0 \\ 19 & 0 & 0 & 0 & 0 \\ 20 & 0 & 0 & 0 & 0\end{array}$


CCR-inefficient units (such as unit 3) are not cost-efficient either. Using the presented inverse model, the value of the target function was obtained 816.350 and the first and intermediate input costs were 0. CCR-efficient units which are not cost-efficient (such as unit 9) have target function of 303.8538 with first cost input values of 170.95 and 41.5463. Their intermediate cost input was 120 and 180 .

Using the new prices, unit 3 became cost-efficient. CCR-efficient units which are also cost-efficient (such as units 2 and 4 ) showed the previous costs. But for the unit 1 which is both CCR- and Cost-efficient, costs of the second and intermediate stages were decreased. Using the new prices, unit 1 is also cost-efficient.

\section{Conclusion}

Using inverse linear programming model, we proposed a new model capable of finding price vectors for CCR-efficient units which were not cost-efficient in a way that they became cost-efficient. We concluded the same for a model in which the intermediate input possessed cost. We even found new price vectors for costefficient units which were lower than their previous prices. The units maintained their cost efficiency with their new price vectors. The major feature of the proposed model is determination of new prices to reach to optimal costs in unit strategy determination; as the cost efficiency constitutes more important information for management and programming on its basis will be more valid. The presented numerical examples showed the superiority of the proposed method over the conventional data envelop analysis methods.

\section{REFERENCES}

[1] Charnes.A., Cooper.W.W. (1962), Programming with Linear Fractional Functional ; Naval Research Logistics Quarterly, 9, 181-185;

[2] Charnes,A. , Cooper, W.W. Rhodes, E.(1978), Measuring the Efficiency of Decision Making Units ; European Journal of Operational Research .2,429-444; [3]Chen,Y., Cook, WD., Li,N., Zhu, J. (2009), Additive Efficiency Decomposition in Two-stage DEA; European Journal of Operational Research, 196: 1170-1176;

[4] Despotis, D K., Koronakos, G., Sotiros, D. (2014), Composition versus Decomposition in Two-stage Network DEA: A Reverse Approach; Journal of productivity Analysis, 45(1):71-87; 
Calculation of Cost Efficiency by Inverse Linear Programming with Two-stage Structure

[5] Fare, F., Grosskopf,S. (2000), Network DEA; Socio- Economic Planning Sciences. 34,35-49;

[6] Farrell, M.T.(1957), The Measurement of Productive Efficiency; Journal of the Royal Statistical Society Series A, 120, III (1957) pp.253-281;

[7] Kao, C.(2014), Network Data envelopment Analysis: A Review ; European Journal of Operational Research. 239,1-16;

[8] Kao,C., Hwang, S-N. (2008), Efficiency Decomposition in Two-stage Data Envelopment Analysis: An Application to Non-Life Insurance Companies in Taiwan ; European Journal of Operational Research. 185:418-429;

[9] Kuhn, H.,Tucker. A. (1950), Non-Linear Programming, Proceedings of the Second Berkeley Symposium on Mathematical Statistics and Probability;

University of California Press, Berkeley, California;

[10] Sadri, S., Rostamy-Malkhalifeh ,M., Shoja,N. (2017), Inverse Linear Programming in Cost Efficiency and Network; Advances And Applications In Statistics.51.131-149;

[11]Seiford, L.M., Zhu,J.(1999), Profitability and Marketability of the Top 55

US Commercial Banks;. Management Science. 45,1270-1288;

[12]Yang, C., Zhang, J. (1999), Two General Methods for Inverse Optimization Problems; Applied Mathematics Letters . 12. 69-72;

[13]Zhang, J., Liu, Z. (1996), Calculating some Inverse Linear Programming

Problems; Journal of Computational and Applied Mathematics.72; 261-273. 